(4) CAse. A roman had her breast amputated for an ordinary scirrhus. It was a hard, firm growth, cut with a clean section, which was of a translucent bluish colour, traversed by threads of an opaque buff (milk ducts). Some highly characteristic cancer-cells were observed in the growth. The operation had hardly been done four or five days before the disease returned in the skin above the operation wound. The secondary formation was removed; it was a grey, semi-transparent, gelatinous, highly vascular and hacmorrhagic substance-in a word, encephaloid. The microscopic characters were those usually seen. She was discharged, with the operation wound cicatrised, in about three weeks after the last operation.

Such a case as this affords strong evidence of the constitutional origin of cancerous deposits. The secondary growth was of a totally different species of cancer to the primary one: hence the former was not a portion of the latter left by an incomplete operation, but would appear to have been called into existence by the irritation of the operation wound reacting upon a strong constitutional predisposition to malignant disease.

(5) The exciting cause of a cancerous tumour is often inappreciable : in the great proportion of cases, inadequate to account for its appearance. In this latter respect, cancerous disease bears a strong analogy to pyæmia. It is not improbable that this latter disease (and even possibly tetanus) may demand a prior special alteration of the general constitution for its actual production.

Turning to the evidence for the local nature of cancerous disease, we are at a loss to determine upon what facts such evidence rests.

(1) That cancerous tumours not uncommonly succeed some local injury? Post hoc, propter hoc. Admitting such an interpretation of the facts of the case, hardly an individual of the human race would be exempt from the fatal mialady.

(2) Some authors have held that the secondary deposits of cancer originated in the first instance from the blood that had become infected by absorbing the cancer-blastema of the primary tumour. The doubtful, if not negative, results obtained in the attempts to inoculate cancer controvert this opinion. Several months ago, Dr. Harley and mysclf instituted experiments on this subject; and, as we intend publishing our results at a future period, I for the present refrain from saying anything more on the subject, than that the possibility of inducing cancer by inoculation is far from proved.

We are, in a word, firmly convinced that cancer is a constitutional disease: that a cancerous tumour may react secondarily upon the system at large, by infecting the blood with cancer-blastema, and so in a limited sense be itself a local evil, we are not prepared to deny. Indeed, under certain exceptional circumstances, there is every reason to beliere that the cancerous diathesis may exhaust itself (die out) in the production of a single tumour; and this secondary source of contamination being removed by a surgical operation, the patient may be permanently cured.

\section{CASE OF RUPTURE OF THE UTERUS DURING PREGNANCY.}

Bj Joseph Grifriths Swayne, M.D., Lecturer on Midwifery in the Bristol Medical School.

[1]ead before the Bath and Bristol Branch, Seplember 25th; 1856.]

Or Wednesday, May 7th, 1856, I received a coroner's order to examine the body of Sarah Williams, the wife of a shoemaker, residing at Pleasant Place, Clarence Road, St. Fhilip's. She was stated to have died during labour; and the relations imputed blame to the parties in attendance upon her. She was 37 years of age, had given birth to six children previously without any difficulty, and had also miscarried twice. Mr. Crosby Leonard kindly assisted me in the post mortem examination. The body was beginning to decompose rapidly, although the examination was not more than twenty-four hours after death. The abdomen especially was much discoloured. Before opening the body, we made a vaginal examination, and found but little shortening of the cervix uteri. The os was high, and diffcult to reach; it would but just admit the index finger. A small hand could be detected presenting at the os internum. On opening the abdomen, we found considerable extravasation of blood between the abdominal parietes and the peritoneum. The peritoneal carity contained some reddish brown serum; the intestines were streaked with red lines of inflammation, and here and there slightly agglutinated; but the quantity of effused lymph was inconsiderable. The uterus had scarcely enlarged sufficiently to rise out of the pelvis: in front of it was a membranous bag, somewhat resembling the bladder; this bag was connected with the uterus behind and the abdominal parietes in front. In attempting to remove the parts, the bag gave way at one point, where it was very thin. We then found that it contained a footus of nearly five months' growth, and very much decomposed. A considerable quantity of blood was extravasated beneath the peritoneum covering the psoas muscles. On removing the parts and examining them, we found a rent in the anterior part of the uterus, where it joins the bladder. It was about two inches in length, and ran obliquely downwards from left to right, extending through the muscular substance, but not through the peritoneal coat. The hand and foot only of the child were contained in the uterus; the rest of it had escaped, together with the placenta, through the rent, and lay between the bladder and uterus, covered by the peritoneum which passes from one to the other. (See diagram.) The bladder was healthy, and contained very little serum. The other viscera were healthy.

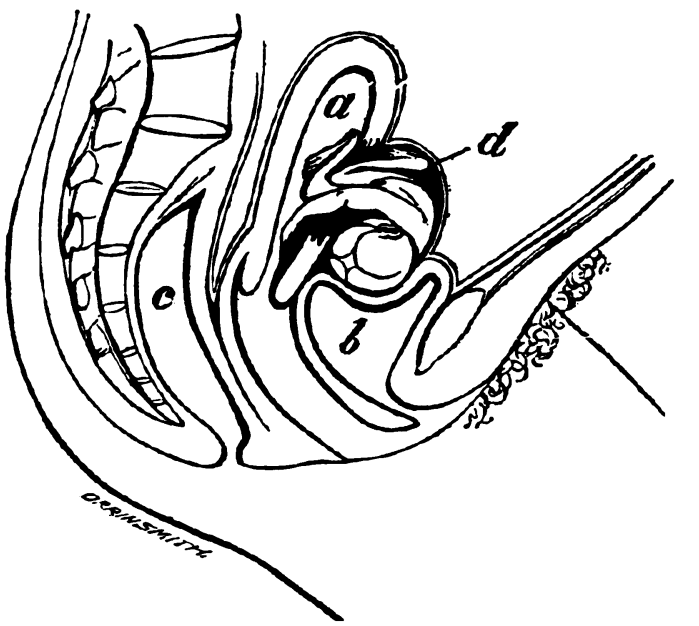

a. Oterus. 8. Bladder. e. Rectum. d. Sac formed by peritoneum containing the fotus.

On making inquiry of the midwife who attended her in the first instance, I learnt that she had a very severe fall about three months before her death, and from that time complained at intervals of pain in the left iliac region. There was also a discharge, which was occasionally profuse, of a dirty offensive watery fluid. At the time of the accident, she considered herself to be seven months pregnant. From that time she appeared to decrease in size, rather than otherwise.

Mr. Parsons, who subsequently attended her, gave me the following history of the case. He first saw her between 9 and 10 A.M. on Sunday, May 4th, three days before her death. He was then informed that a midwife had seen her, and had gone away. She had at that time a slight bloody discharge coming from her. There were scarcely any pains properls so called, but rather an abdominal tenderness, which was increased on pressure. The os uteri was not sufficiently dilated to admit the tip of the finger, and 
no presentation could be felt. The woman was ohilly; her countenance was blanched, and her pulse weak and compressible. Mr. Parsons went awry, and saw her again at 12. She then seemed better; the pain was less, and the discharge had ceased. He again left her, with orders to send for him, if required. They sent for him on the morning of the following day. Mr. Parsons was then engaged with another patient, and advised them to get some medical man nearer at hand. However, they again sent for him in the afternoon of the same day, when, being disengaged, he saw her about 4 P.X. At that time, symptoms of peritonitis were present. There was great abdominal tenderness, especially between the umbilicus and pubis, and much prostration of strength. There were no labour pains, and no presentation could be felt. Mr. Parsons ordered six leeches to be applied to the abdomen, and a poultice afterwards; and gave her a dose of Battley's liquor opii sedatirus, and also some hydrargyrum cum creta. He left her about 9 P.M. On Tuesday morning, he was again summoned to her, and went immediately, but found her dead when he arrived.

The coroner's jury returned a verdict of death from natural causes, and exonerated the partics in attendance from any imputation of neglect.

REXARKs. Instances of ruptured uterus during pregnancy are of rare occurrence; but a case like that above described, where the fotus occupied so peculiar a position after its escape from the uterus, is, I believe, unique. In most cases, rupture of the uterus during gestation has been the result of some obvious cause, such as blows or direct violence,* abscess, or other organic disease of the walls of the uterus, etc. In some cases, it has occurred without any assignable cause, and has then been attributed to irregular action of the uterine fibre, as in that related by $\mathbf{M r}$. Scott of Bromley (Medical Repository, rol. vii), where the patient was awakened from sleep by it. In another case described by Mr. Glen of Brompton, and quoted in Dr. Merriman's Synopsis, the accident appeared to have been occasioned merely by stooping. In the casc I have read, there was much obscurity both as to the cause of the rupture, and the time when it occurred. According to the midwife's account, the woman had a severe fall as much as three months before her death. At that time she considered herself seven months pregnant, but this must have been an error. The development of the uterus and fotus both show that, at the time when the death of the latter took place, she could not have been more than five months pregnant, Conception having taken place during lactation, she had no certain data from which to reckon the commencement of pregnancy. The fall which she experienced most probably caused the death of the fotus, as the abdomen shortly afterwards subsided, and ceased to increase; and an offensive discharge began to escape from the vagina. The rupture of the uterus, however, could not have taken place much more than three days before death; for on Saturday, May 3rd, four days before her death, she was stated to have been as well as usual, and able to attend to her ordinary household duties. On the third day before her death, when Mr. Parsons first saw her, rupture of the utcrus appeared to have taken place, if we may judge from the symptoms which were present, viz., bloody discharge from the vagina, abdominal tenderness, and collapse.

As to the cause of the rupture, it is as difficult to assign as the exact date of its occurrence. The state of the os uteri seems to show that there had been some slight attempts at labour; but the labour pains could scarcely have been sufficiently sevcre to cause rupture by their irregular action. It did not appear that the accident arose from any external injury, for there were no marks of such on the body, and the careful inquiries of the coroner failed to elicit any evidence of violence. There was no thinning of the nterine parietes in the neighbourhood of the rent; and, on cutting into it, the tissue of that part appeared to be as firm and sound as that of the rest of the organ.
On examining the tissue under the microscope, and comparing it with that of a healthy uterus two days after dofivery, there were some appearances of fatty degeneration, but still not sufficiently marked to enable one to say that they were not the result of those changes which ordinarily take place in the uterine tissue after delivery. Hence the cause of the rupturc appears to be veiled in as much obscurity as the other phenomena which were olserved in this extraordinary case.

\section{CASE OF COMPLICATED PRESENTATION.}

By Edward Garbaway, Esq., Faversham, Kent.

Tis following is a sequel to my case of puerperal convulsions reported in the Associatios JoURisu for the 27th of September.

Mrs. N., the patient whose case has been already described, continued in the same state, with albuminous urine, slight anasarca of the face, hands, and feet, more or less pain in the head, and drowsiness, up to Wednesday, September 24th, when, she having rather more than completed her seventh month, I was informed that labour had commenced. The pains had been gradually increasing in force and frequency for about twelve hours, and were moderately vigorous when I arrived. My patient appeared in excellent spirits, and expressed her confidence that I should stecr her safely through. On examination, the vagina was found distended with an elongated pouch of membranes, filled with liquor amnii, and slightly constricted above by the os uteri, which was but little dilated, and very thick and rigid. The whole of the fluid contents of the uterus appeared to have gravitated into the lower part of this pouch, its neck being undistended and flaccid. The os would just admit the points of two fingers, and appeared to be occupied by coils of funis. I never, however, was so much at fault in determining a presentation; in fact, I was fain to content myself with certain negative eridence. It was not the head, nor the feet, nor the hands; I inclined to the scrotum and breech, but at the same time feared the position of the child might be really transverse. Turning, then, would doubtless be necessary; but, as no facility could be afforded to this operation by the liquor amnii, already extruded from the uterus, I ruptured the pouch of membranes, hoping that, as the os dilated, more light would be thrown upon the presenting part. Happily, there was not the slightest threatening of convulsion. I left my patient for an hour.

On my return, the nurse told me that there had been a little disposition to flooding, and showed me one or two clots. On examination, I found coagula in the vagina, and the os, now rather more dilated, occupied by two coils of funis and a flap of placenta, which protruded an inch and a half. No matter now what the position of the child, the state of the placenta demanded immediate delivery. On getting through the os and its entanglements, I found both hands and feet to choose from, for they were all presenting; and, selecting one of the lattcr, effected the delivery without further trouble. The child was small and dead. There was no hæmorrhage, no convulsion.

September 28th. Mrs. N. is now (the fifth day) convalescing. She, however, still complains of pain and some confusion in the head, and the urine continues albuminous.

REMARKs. The points of interest in this case were:1. The small amount of hæmorrhage from the flap of detached placenta. 2. The complex presentation, viz., placenta, two loops of funis, hands and feet (something extenuatory of the accoucheur's bungling diagnosis). 3. The absence of convulsions, which, considering the woman's antecedents, appeared almost inevitable, and which might fully and fairly have been expected to occur upon the introduction of the hand into the womb, if not before. 